\title{
Treatment and outcome of unusual animal bite injuries in young children
}

\author{
P de Klerk, ${ }^{1}$ BSc; M van Dijk, ${ }^{2} \mathrm{PhD} ; \mathrm{A}$ B van As, ${ }^{3} \mathrm{PhD}$ \\ ${ }^{1}$ Department of Pediatric Surgery, Erasmus University, Rotterdam, Netherlands \\ ${ }^{2}$ Department of Pediatric Surgery and Paediatrics, Erasmus MC-Sophia Children's Hospital, Rotterdam, Netherlands \\ ${ }^{3}$ Department of Paediatric Surgery, University of Cape Town, Red Cross War Memorial Children's Hospital, Cape Town, South Africa
}

Corresponding author: P de Klerk (peterdeklerk@live.nl)

Background. Animal bites are a major cause of preventable traumatic injuries.

Objectives. To provide more epidemiological information on animal bites, and assist in increasing awareness of the problem.

Methods. A retrospective chart review was performed including children aged $>13$ years presenting with bite injuries (excluding dog and human bites) to the trauma unit at Red Cross War Memorial Children's Hospital, Cape Town, South Africa, over a 25-year period.

Results. Two hundred and thirteen children were eligible to be entered into the study. The median age was 2.9 years (range 1.2 - 6.5), with boys slightly predominating (54.9\%). Most (74.6\%) of the bite injuries were inflicted by mammals, the majority (64.8) of mammalian bites being rat bites. The proportions of boys and girls in the age group $0-4$ years bitten by rats significantly differed from the proportions in the age group $>4$ years $(p=0.039)$. In the age group 0 - 4 years more girls suffered rat bites, while more boys were bitten in the age group $>4$ years. Of 91 rat bites, $81(89.0 \%)$ occurred inside the house. The hands (43.9\%) and the head/face/neck region (39.0\%) were most affected. The underdeveloped suburbs of Philippi, Gugulethu and Khayelitsha in Cape Town represented a disproportionate number (41.6\%) of rat bites. Conclusions. There is a relationship between poverty, unemployment, poor housing, informal settlements and rodent infestation. These high-risk populations need to be the target for government rat eradication programmes.

S Afr Med J 2016;106(2):206-209. DOI:10.7196/SAMJ.2016.v106i2.10106

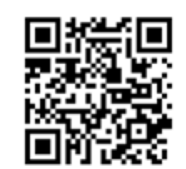

Animal bites are a major cause of preventable traumatic injuries, and most reported cases involve children. ${ }^{[1]}$ There is no accurate epidemiological information, as not all people who are bitten seek medical care. ${ }^{[2]}$ Previously reported studies have focused mainly on dog bites. ${ }^{[2-5]}$ Rat bites have, however, become an increasing problem in informal settlements. ${ }^{[6]}$ Not only do these bites cause severe trauma, but rats are important vectors of a variety of diseases, including leptospirosis, lassa fever, rat-bite fever, viral haemorrhagic fevers, bartonelosis, plague, murine typhus and salmonellosis. ${ }^{[7,8]}$ Younger children $(<5$ years $)$ in particular tend to be the victims of rat bites, typically in their beds as they sleep during the night.

There is a strong association between the incidence of rat bites and poverty in urban areas. In Philadelphia and New York City, USA, the highest incidences were found in areas with high unemployment, low family income and old housing structures. ${ }^{[9,10]}$ Poor sanitation and drainage, open drains and improper storage of food and garbage make food and water available for rats, while their nesting and breeding is promoted by the poor conditions of the houses. ${ }^{[6,7,11]}$ Poor living conditions such as those in the informal settlements in South Africa (SA) are conducive to rodent infestation. SA therefore represents a high-risk area requiring implementation of prevention programmes.

The current study was designed to provide insight into and epidemiological information on unusual animal bites, rat bites in particular. We believe that publication of these results will enhance awareness of the problem.

\section{Methods}

This retrospective chart review included children $<13$ years of age presenting with bite injuries to the trauma unit at Red Cross War
Memorial Children's Hospital (RCWMH), Cape Town, SA, during the 25-year period 4 January 1991 - 14 March 2015.

Exclusion criteria were dog bites, human bites, bites associated with falls, tongue bites, unknown types of bite, and trauma causes other than bites.

\section{Research procedure and data collection}

Patient details were retrieved from the Child Accident Prevention Foundation of South Africa (CAPFSA) database, in which the entry 'other bites' was used to identify our study population.

From this database the following variables were extracted: gender, age at the time of the bite incident, date of the incident, the child's first language, demographic characteristics, type of bite wound, description of the bite incident (e.g. (indoor/outdoor) and time, anatomical site of the bite injury, pathology, severity assessed with the Abbreviated Injury Score (AIS) (minor, moderate, severe, mortal), treatment (medication, immunisation, analgesic, wound dressing, sutures, stitches, debridement, amputation, skin graft, etc.), follow-up (returned for check-up), socioeconomic background, family income and parental employment.

Statistical information on the different regions in Cape Town was extracted from a report published by the City of Cape Town in $2011^{[12]}$

\section{Data analysis}

Normally distributed variables were presented as means (standard deviation) and non-normally distributed variables as medians (interquartile range (IQR)). Numbers of rat bites were compared between gender and age groups using Fisher's exact test. The data analyses were performed using SPSS Statistics 23.0 (IBM, USA). A $p$-value of $<0.05$ was considered statistically significant. 


\section{Results}

In the CAPFSA database, 450 patients were identified with the entry 'other bite', 237 of whom were excluded because they did not meet the inclusion criteria or there was an exclusion criterion. Table 1 presents the background characteristics of the 213 patients included in the study. The median age was 2.9 years (IQR $1.2-6.5$ ), and 117 (54.9\%) were boys. In 107 cases the patient's racial category was identified: 20 children $(18.7 \%)$ were categorised as black, 21 $(29.6 \%)$ as white and $66(61.7 \%)$ as coloured (of mixed race).

Mammals inflicted most of the bite injuries $(159 / 213,74.6 \%)$. Thirty-nine children $(18.3 \%)$ were bitten by insects, 8 (3.8\%) by species of birds (e.g. chickens), and 7 (3.3\%) by snakes.

Fig. 1 is a pie chart of all the mammalian bite injuries, divided into the different species. It is clear that most bite injuries were inflicted by rats. The boxplot in Fig. 2 presents the ages of the children at the time of the bite incident, categorised by type of animal. The children bitten by rats had the lowest median age (1.5 years, IQR 1.5 - 3.3).

\begin{tabular}{ll}
$\begin{array}{l}\text { Table 1. Background characteristics of } \\
\text { the patients }\end{array}$ \\
\hline Patients & $\boldsymbol{n}(\%)$ \\
\hline Age at incident (years) & \\
$0-2$ & $80(37.6)$ \\
$2-4$ & $44(20.7)$ \\
$4-6$ & $26(12.2)$ \\
$6-8$ & $27(12.7)$ \\
$8-10$ & $19(8.9)$ \\
$>10$ & $17(8.0)$ \\
Total & $213(100.0)$ \\
Gender & \\
Male & $117(54.9)$ \\
Female & $96(45.1)$ \\
Total & $213(100.0)$ \\
Race & \\
Black & $20(18.7)$ \\
White & $21(19.6)$ \\
Coloured & $66(61.7)$ \\
Total & $107(100.0)$ \\
First language & $32(38.6)$ \\
Xhosa & $20(24.1)$ \\
Afrikaans & $30(36.1)$ \\
English & $1(1.2)$ \\
French & $83(100.0)$ \\
Total & \\
& \\
\hline &
\end{tabular}

Of the 103 children who were bitten by a rat, 57 (55.3\%) were girls and $46(44.7 \%)$ were boys. Of these, 51 girls (49.5\%) and 33 boys $(32.0 \%)$ fell into the age category 0 - 4 years, while 13 boys (12.6\%) and 6 girls $(5.8 \%)$ were aged $>4$ years. Fisher's exact test showed a significant difference between the proportions of boys and girls aged $\leq 4$ years and those aged $>4$ years $(p=0.039)$.

In 198 cases, the geographical place where the bite occurred was documented. Of all animal bites, the largest proportion (61.6\%) occurred inside the house. Bites inflicted by birds occurred most frequently outdoors (62.5\%), whereas bites by mammals occurred more frequently inside the house $(69.2 \%)$ (Table 2). The place of occurrence could be identified for 91 out of the 103 rat bites; of these, $81(89.0 \%)$ occurred inside the house. Of all the 213 patients, $180(84.5 \%)$ presented to hospital between $07 \mathrm{~h} 00$ and $22 \mathrm{~h} 00$.

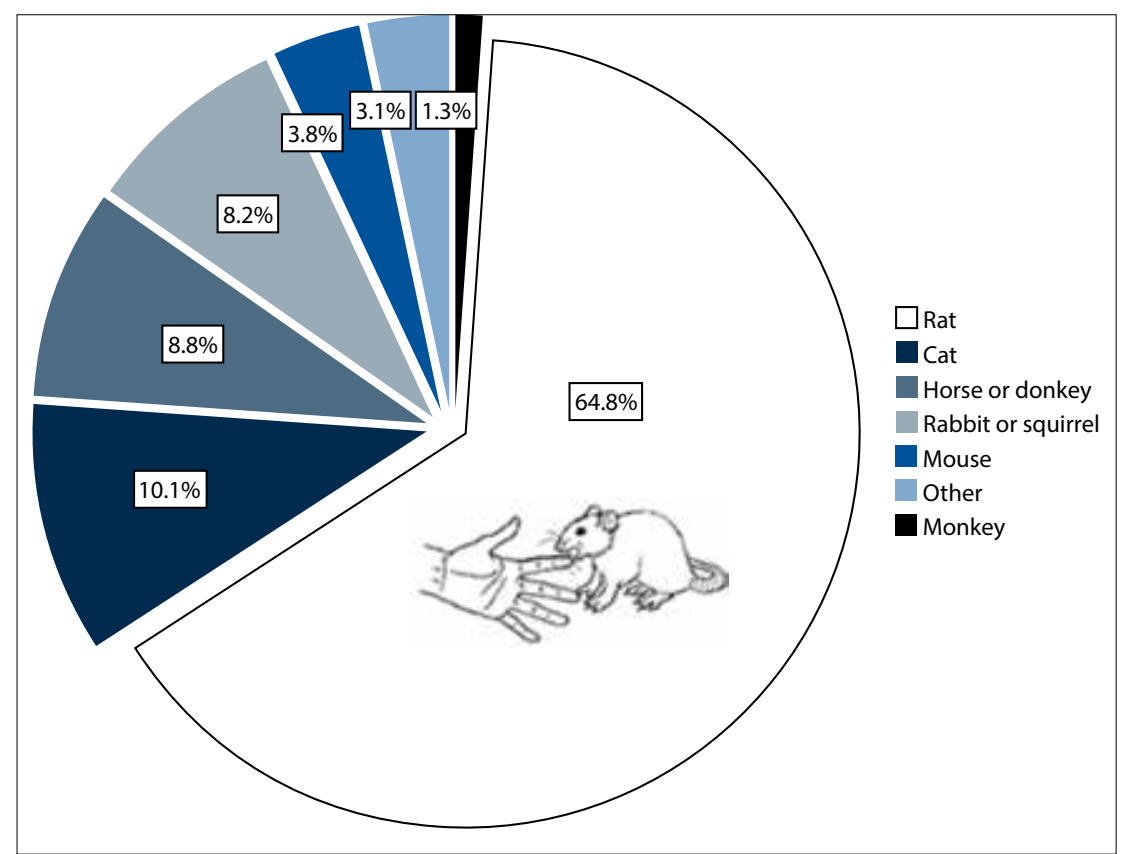

Fig. 1. Mammalian bite wounds by animal species.

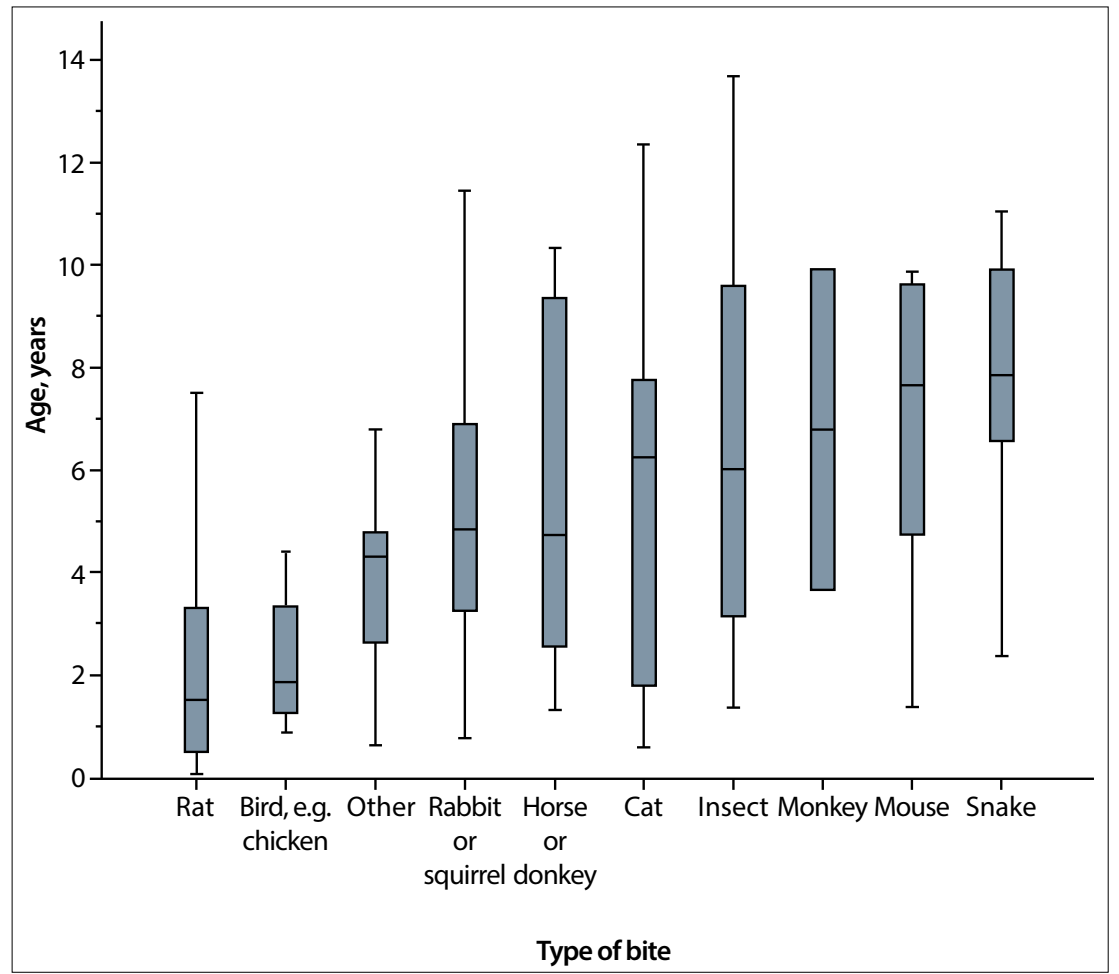

Fig. 2. Ages of the children at time of the bite incident. 
Some patients had more than one bite, and there were 223 bites in total. We categorised the bite injuries into seven anatomical sites. Fig. 3 shows that the most commonly injured anatomical sites were the hands (43.9\%) and the head/face/neck (39.0\%).

Information concerning treatment, medication and analgesics was documented in 91 cases. Forty-five patients (49.4\%) received tetanus immunisation (in 10 cases $(11.0 \%)$ this immunisation was already up to date). Rabies vaccination was reportedly given to only 8 children $(8.8 \%)$. Thirteen patients (14.3\%) received antibiotics, and 1 patient was treated with prednisone and 1 with ibuprofen. Analgesics were administered to 28 patients $(30.8 \%$ ) (paracetamol $n=21$, pilidine $n=5$, diclofenac $n=2)$.

Of all the 213 patients, $180(84.5 \%)$ were classified as having AIS minor injuries, 28 as having moderate injuries and 5 as having severe injuries. Surgery was reported in 3 of the 5 severe cases and 8 of the 28 moderate cases. Six surgical procedures encompassed wound debridement, 1 patient needed a fasciotomy and 4 patients required skin grafting. Two rat bites classified as moderate/ severe injuries and described as a 'deep bite in lower end of finger' necessitated amputation of a fingertip. One child with a snakebite to the leg had clinical signs of a compartment syndrome (extensively swollen, tender and tense calf, decreased sensation to touch and calf pain on dorsiflexion of the foot) and fasciotomy was required to release the pressure in the compartment, with subsequent skin transplantation.

\section{Area statistics for rat bites}

The area code was recorded for 101 rat bites $(98.1 \%)$. Forty-two rat bites $(41.6 \%)$ occurred in the suburbs of Philippi $(n=20)$, Gugulethu ( $n=12)$ and Khayelitsha $(n=10)$. The other rat bites occurred in 23 other areas throughout Cape Town. The population size, demographic profiles, economic profiles and dwelling profile of Philippi, Gugulethu and Khayelitsha are set out in Table 3.

\section{Follow-up}

In 28 cases, information concerning followup was documented. Twenty children were followed up by social workers, who reported that the children bitten by rats lived in informal settlements under poor socioeconomic circumstances, their families living in shacks or 'Wendy houses', with children frequently sleeping on a dilapidated wooden floor. Some families' dwellings were close to drains or on farms adjacent to open fields. It was confirmed that there were rat problems in these areas: 'huge rat problem in the area';

Table 2. Geographical place of occurrence in relation to type of bite $(N=198)$

\begin{tabular}{llll}
\hline Type of bite & $\begin{array}{l}\text { Home, indoors } \\
\boldsymbol{n}(\%)\end{array}$ & $\begin{array}{l}\text { Outdoors } \\
\boldsymbol{n}(\%)\end{array}$ & $\begin{array}{l}\text { School/public place } \\
\boldsymbol{n}(\%)\end{array}$ \\
\hline Mammal & $101(69.2)$ & $34(23.3)$ & $11(7.5)$ \\
Insect & $16(42.1)$ & $14(36.8)$ & $8(21.1)$ \\
Bird & $2(25.0)$ & $5(62.5)$ & $1(12.5)$ \\
Snake & $3(50.0)$ & $3(50.0)$ & $0(0.0)$ \\
Total & $122(61.6)$ & $56(28.3)$ & $20(10.1)$
\end{tabular}

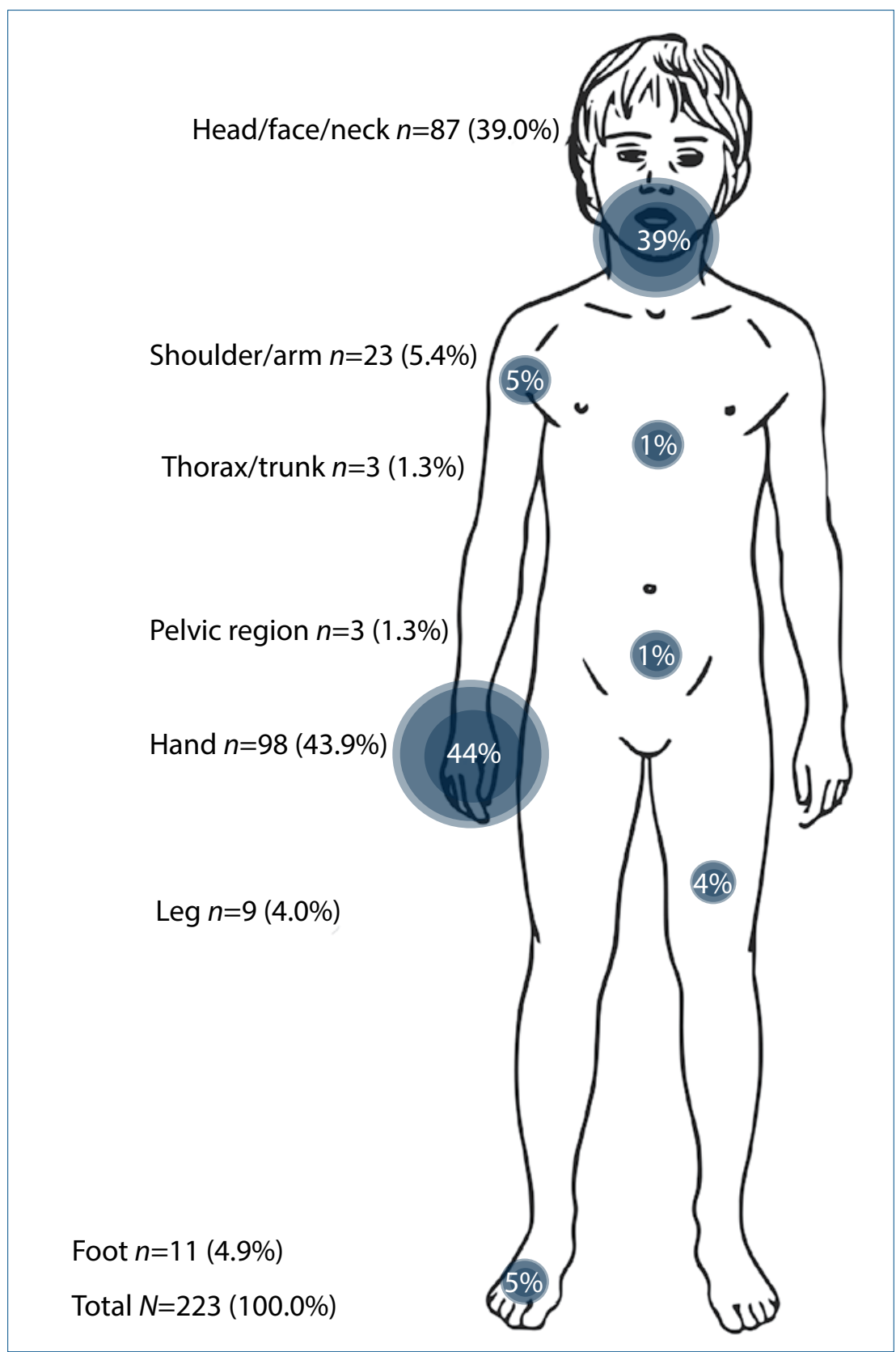

Fig. 3. Anatomical sites of the bites.

'similar problems in the past'; 'big rats come out during the night time and bite children'.

Social workers sometimes reported that more than one family member had been bitten: 'brother was bitten previously by a rat'; 'all four children have been bitten by rats previously'. There were also reports, albeit rare, that the mother was intoxicated with alcohol and therefore failed to respond to the child's crying. 
Table 3. Demographic data on the suburbs of Philippi, Gugulethu and Khayelitsha

\begin{tabular}{lllll}
\hline Suburb & Population size, $\boldsymbol{N}$ & Income $<$ ZAR3 200, \% & $\begin{array}{l}\text { Black } \\
\text { Africans, \% }\end{array}$ & $\begin{array}{l}\text { Informal } \\
\text { dwellings, \% }\end{array}$ \\
\hline Philippi & 191025 & 78.2 & 94 & 55.6 \\
Gugulethu & 391749 & 73.7 & 99 & 54.5 \\
Khayelitsha & 98468 & 71.4 & 99 & 47.1
\end{tabular}

\section{Discussion}

A disproportionate number of the rat bite victims lived in Philippi, Gugulethu and Khayelitsha, which are disadvantaged areas. Our findings indicated that around 50 $55 \%$ of the households lived in informal dwellings and $70-80 \%$ lived in poverty (surviving on <ZAR3 200 per month). Several studies have reported that poor socioeconomic circumstances, unemployment, living below the poverty line, poor sanitation and drainage, open drains, overcrowding of homes, poor/informal housing and environmental conditions that provide food, water and shelter for rodents are linked to rodent infestation. ${ }^{[6-11,13,14]}$ Previous reports have documented that rodent bites occur most frequently in areas with high rates of poverty and unemployment. ${ }^{[6,10]}$ Rodents are a significant problem in urban settlements in Johannesburg, especially in the poor areas. ${ }^{[6]}$ These findings are consistent with our results.

RCWMH is a tertiary-level referral hospital that treats only severe and referred cases. Since not all victims of bite injuries are referred to a healthcare institution for medical treatment, ${ }^{[15]}$ it is probable that the cases seen at RCWMH represent the tip of an iceberg.

In this study, $54.9 \%$ of the children presenting after animal bite injuries were boys. This is consistent with the literature, most studies on animal bite injuries reporting a male predominance. ${ }^{[15-18]}$ In contrast to this finding, we found that in the age group 0 - 4 years, girls were more likely to be bitten by rats. Furthermore, most of the rat bites occurred in the youngest age group. This may be explained by the fact that children in this age category, perhaps girls in particular, are not capable of protecting themselves from rats. Parents or other caregivers must therefore take adequate precautions to prevent these injuries to young children.

The head (face) and hands were the anatomical locations most affected by animal bite injuries. This is in agreement with other

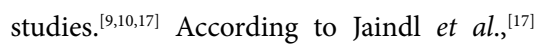
young children may be vulnerable because they do not yet understand the behaviour of animals, while their short stature exposes their faces and hands and makes them easier targets. Hirschhorn and Hodge's ${ }^{[10]}$ observation that most bite injuries occur in sleeping children would also offer an explanation why the face and hands were most affected, these body parts being more exposed during sleep.

The finding that most mammalian bites occurred inside the house is explained by the predominance of rat bites, of which $84 \%$ are known to occur indoors. ${ }^{[10]}$ This in turn is explained by the fact that families of victims of rat bites typically live in informal settlements, in shacks with dilapidated floors.

In the present study, almost $50 \%$ of the children received a tetanus vaccination. The guideline for tetanus immunisation is the same for animal bites as for any other injury that penetrates the epidermis. ${ }^{[1]}$ We found that just over $14 \%$ of the animal bites were treated with antibiotics, in line with a previous study. ${ }^{[17]}$ While there is no scientific evidence for the benefits of antibiotic prophylactic therapy in animal bites, ${ }^{[1,9,19]}$ antibiotics tend to be prescribed to patients with deep puncture wounds and high-risk immunocompromised patients. ${ }^{[1,19]}$ A deep wound generally also requires extensive cleaning, debridement and suturing, and in some cases skin grafting. ${ }^{[1]}$

Dealing with the public health issue of rodent bite injuries in children requires development of preventive strategies that target the population at risk. Rodent control programmes are often understaffed and fail to address the fundamental underlying problems. ${ }^{[6]}$ While education of families will create awareness of this community health problem, and rodent eradication programmes are important, they are unlikely to be sufficient. What needs to be achieved is an improvement in housing quality, prevention of overcrowding and installation of proper sanitation and drains, while at the same time addressing the scourges of poverty and unemployment. This can only be achieved over the long term.

\section{Conclusions}

There is a relationship between poverty, unemployment, poor housing, informal settlements and rodent infestation. Recognisable high-risk populations need to be targeted for public health rat eradication programmes that should include improved domestic hygiene, the safe storage of garbage, and sanitation control.

\section{References}

1. Kannikeswaran N, Kamat D. Mammalian bites. Clin Pediatr 2009;48(2):145-148. [http://dx.doi.org/10.1177/0009922808324494]

Schalamon J, Ainoedhofer H, Singer G, et al. Analysis of dog bites in children who are younger than 17 years. Pediatrics 2006;117(3):e374-el19. [http://dx.doi.org/10.1542/peds.2005-1451]

3. Dwyer IP, Douglas TS, van As AB. Dog bite injuries in children -

a review of data from a South African paediatric trauma unit. $S$ Afr Med J 2007;97(8):597-600.

4. Griego RD, Rosen T, Orengo IF, Wolf JE. Dog, cat, and human

bites: A review. J Am Acad Dermatol 1995;33(6):1019-1029. [http://dx.doi.org/10.1016/0190-9622(95)90296-1]

Sacks JJ, Lockwood R, Horneich J, Sattin RW. Fatal dog attacks Sacks JJ, Lockwood R, Hornreich J, Sattin RW.
1989-1994. Pediatrics 1996;97(6):891-895.

6. Jassat W, Naicker N, Naidoo S, Mathee A. Rodent control in urban communities in Johannesburg, South Africa: From research to action. Int J Environ Health Res 2013;23(6):474-483. [http://dx.doi.org/10.1080/09603123.2012.755156]

7. Roomaney R, Ehrlich R, Rother HA. The acceptability of rat trap use over pesticides for rodent control in two poor urban communities in South Africa. Environ Health 2012;11:32. [http://dx.doi.org/10.1186/1476-069X-11-32]

8. Kajdacsi B, Costa F, Hyseni C, et al. Urban population genetics of Kajdacsi B, Costa F, Hyseni C, et al. Urban population genetics of slum-dwelling rats (Rattus norvegicus) in Salvador, Brazil. Mol Eco

2013,22(20) 5056-50. [h/p//x.dolorg/10.111/mec.12455]

Childs JE, McLafferty SL, Sadek R, et al. Epidemiology of rodent bites and prediction of rat infestation in New York City. Am J Epidemiol 1998;148(1):78-87. [http://dx.doi.org/10.1093/ oxfordjournals.aje.a009563]

10. Hirschhorn RB, Hodge RR. Identification of risk factors in rat bite incidents involving humans. Pediatrics 1999;104(3):e35. [http://dx.doi.org/10.1542/peds.104.3.e35]

11. Bonner PC, Schmidt WP, Belmain SR, Oshin B, Baglole D, Borchert M. Poor housing quality increases risk of rodent infestation and Lassa fever in refugee camps of Sierra Leone. Am J Trop Med Hyg 2007;77(1):169-175.

12. City of Cape Town - 2011 Census Suburb: City of Cape Town. 2011. https://www.capetown.gov.za/en/stats/Pages/2011-CensusSuburb-Profiles-land.aspx (accessed 8 July 2015).

den in urban Delhi. Mehndiratta S. Animal bites in children: Burden in urban Delhi.
Trop Doct 2012;42(2):114-115. [http://dx.doi.org/10.1258/ Trop Doct 2012

14. De Masi E, Vilaca P, Razzolini MT. Environmental conditions ae Masi E, Vilaca P, Razzolini MT. Environmental conditions
and rodent infestation in Campo Limpo district, Sao Paulo and rodent infestation in Campo Limpo district, Sao Paulo
municipality, Brazil. Int J Environ Health Res 2009;19(1):1-16. [http://dx.doi.org/10.1080/09603120802126670]

15. Dendle C, Looke D. Animal bites: An update for management with a focus on infections. Emerg Med Australas 2008;20(6):458467. [http://dx.doi.org/10.1111/j.1742-6723.2008.01130.x]

16. Fleisher GR. The management of bite wounds. N Engl J Med 1999;340(2):138-140. [http://dx.doi.org/10.1056/ NEJM199901143400210]

17. Jaindl M, Grunauer J, Platzer P, et al. The management of bite wounds in children - a retrospective analysis at a level I bite wornds in cildren a retrospective analysis at a level I trauma centre. Injury 2012;43(12):2117-2121. [http://dx.doi.

Deforimal bite wounds. 18. Goldstein EJ. Management of human and animal bite wounds.
J Am Acad Dermatol 1989;21(6):1275-1279. [http://dx.doi. J Am Acad Dermatol 1989;21(6):1275-
org/10.1016/S0190-9622(89)70343-1]

19. Morgan M. Hospital management of animal and human bites. J Hosp Infect 2005;61(1):1-10. [http://dx.doi.org/10.1016/j. jhin.2005.02.007]

Accepted 14 October 2015. 